\title{
Thermal modification of most representative Portuguese wood species. A preliminary study
}

João C. Costa (Main Author)

Institute for sustainability and Innovation in Structural Engineering (ISISE)

Department of Civil Engineering, University of Minho

4800-058 Guimarães (Portugal)

jcosta.engcivil@gmail.com

Jorge M. Branco (Corresponding Author)

ISISE, Department of Civil Engineering, University of Minho

4800-058 Guimarães (Portugal)

jbranco@civil.uminho.pt

Aires F. Camões

CTAC, Department of Civil Engineering, University of Minho

4800-058 Guimarães (Portugal)

aires@civil.uminho.pt

Manuscript Code: 1315

Date of Acceptance/Reception: 25.11.2019/23.01.2019

DOI: 10.7764/RDLC.18.3.488

\begin{abstract}
The thermal modification has proved to be an effective method to improve the durability of wood elements. Until now, most applications of thermally modified wood have been limited to non-structural applications since the wood's heat treatment leads to a significant reduction in mechanical performances. However, there is no knowledge about these treatments applied on the wood species more used in Portuguese constructions. In order to evaluate the effect of heat treatment on the wood species of Maritime pine (Pinus pinaster), Eucalyptus (Eucalyptus globulus), Beech (Fagus sylvatica), Acacia (Acacia melanoxylon) and Oak (Quercus faginea), an experimental program consisted of mechanical bending tests and dimensional stability tests (shrinkage, swelling and equilibrium moisture content) was defined. For comparison purposes, all tests were made with test specimens of non-modified and thermally modified wood using four temperature values $\left(200^{\circ} \mathrm{C}, 240^{\circ} \mathrm{C}, 260^{\circ} \mathrm{C}\right.$ and $\left.300^{\circ} \mathrm{C}\right)$ and three exposed periods $(2,4$ and 8 hours). The obtained results show that the behaviour of the studied experimented species was similar to the one of other species already studied in the available literature. It was possible to point out that mechanical properties decrease with the severity of the thermal treatment, while the dimensional stability improved.
\end{abstract}

Keywords: Thermal modification, experimental evaluation, strength, dimensional stability.

Introduction

The use of wood as a construction material is not new. Its low weight, good strength and its easiness to work with made it a permanent material in the evolution of mankind. With the advance of technology, wood construction solutions have diversified and, nowadays, it is possible to find wood in all types of constructions, as a coating material or for structural purposes.

As with every organic material, wood can be affected by several types of deterioration agents under suitable climate exposure conditions, which entails most of the time biological degradation, physical and chemical damage. Once they appear, wood deterioration can compromise at different levels the safety and long-term performance of timber structures, by reducing their service life. Therefore, it is crucial to spot and prevent the development of different wood deterioration agents likely to occur in timber structures in service as per their climate exposure conditions (Verbist et al., 2018).

Impregnation of the wood with chemical substances toxic to fungi and bacteria is one of the most commonly used methods of preservation. One major drawback of this method is that it is toxic to many other organisms as well. These preservatives do not prevent problems with dimensional instability. There are, however, methods to stabilize lumber chemically, but these are very expensive, and the substances used can also, in some cases, be questionable in terms of their environmental effects. 
Heat treatment is an alternative process for improving wood less desirable properties as poor durability and poor dimensional stability with no use of chemical additives (Johansson, 2008).

Thermal modification consists of exposing wood to temperatures between $160 \circ \mathrm{C}$ and $260 \circ \mathrm{C}$ to increase both dimensional stability and resistance to decay. By restricting its hygroscopic behaviour, the equilibrium moisture content $(E M C)$ is reduced, leading to a better dimensional stability. At the same time, a lower EMC leads to another benefit: the increase of biodegradation resistance (Jämsä \& Viitaniemi, 2001; Esteves, 2006, Esteves et al., 2007; Hakkou et al., 2006; Rapp, 2001; Finnish ThermoWood Association, 2003; Hill, 2006; Pentti et al., 1993). By improving these properties, the good performance of wood is prolonged, proving that thermal treatment is an effective method to increase wood durability (Esteves et al., 2013; Hill, 2006; Pentti et al., 1993; Rapp, 2001) and can further promote the use of wood in construction as result of an improvement on the durability and dimensional stability.

The new properties conferred to thermally modified wood (TMW) depend directly on the level of degradation caused by high temperatures of thermal treatment and its endurance (Johansson, 2008). The EMC and the oxygen content decrease progressively as the intensity of the treatment increases, while dimensional stability increases. Extractives generated during thermal treatment process cause none or very weak antifungal activities. A wood thermo-degradation level between $10 \%$ and $15 \%$ is required to achieve full durability for brown rot fungi, which is the result of chemical modifications that occur in wood during heat treatment (Chaouch et al., 2012). These modifications include hemicelluloses degradation and lignin net modifications that indirectly influence the EMC and the dimensional stability. Increased dimensional stability, often in a range of values that exceed $60 \%$, contributes to the proper functioning of links and different construction solutions (Esteves \& Pereira, 2009; Burmester, 1975).

Thermal treatment is also known for reducing the mechanical properties of wood, due to the degradation of some compounds like lignin, cellulose and hemicellulose that play an important role in mechanical performance (Hill, 2006; Esteves et al., 2013). The more intense the treatment is, the higher is the loss of those wood constituents (Militz \& Tjeerdsma, 2000; Boonstra et al., 1998). Decrease hemicellulose content leads to a similar reduction of the bending strength. A decrease of $50 \%$ on bending strength was notably obtained due to the $50 \%$ inferior hemicellulose content of thermally modified pine. In other studies, the modulus of elasticity was affected up to $5 \%$ for pine and up to $15 \%$ for eucalyptus but the bending strength was impaired as a result of hemicelluloses and celluloses degradation of up to $40 \%$ for pine and $50 \%$ for eucalyptus, in the most severe thermal treatments (Esteves et al., 2006; Rapp, 2001; Bal, 2014). Vukas et al. (2010) indicates that the degradation of the polysaccharide would result in a significant reduction of all the mechanical properties of wood, such as bending strength of pine and oak that experimented a reduction of $10 \%$ to $30 \%$, thus increasing their brittleness.

Through the study of different wood species present in Portugal submitted to thermal modification, it is expected to understand with accuracy the effects of heat treatment on those wood species, in particular, the mechanical properties reduction and the improvement in the dimensional stability, because these know-how is missing.

Besides, in order to enhance TMW applications, it is essential to deepen the studies that will allow to define thermal modification classes by its severity and changes caused in the wood species. In fact, past researches performed with wood species present in Portugal were focused on the study of the influence of thermal treatment in both dimensional stability and EMC (Rodrigues et al., 1998; Esteves et al., 2013; Esteves et al., 2006) but few studies are known to assess the influence on its mechanical properties.

The main goal of the present work is to study the properties of the material (wood) submitted to thermal treatment by using the most important wood species available in Portugal: Maritime pine (Pinus pinaster), Eucalyptus (Eucalyptus globulus), Beech (Fagus sylvatica), Acacia (Acacia melanoxylon) and Oak (Quercus faginea). The first two are the most common species used in wooden constructions in Portugal, while beech is the species most used in TMW. Acacia is a very fast growing species but with a low grade value and Oak is very common in ancient buildings considered as Cultural Heritage. The properties evaluated are: EMC, dimensional stability, mass loss and bending.

Methodology

For each wood species evaluated in this experimental program, all test specimens used were taken from the same sample. After being air dried and cut, they were transported to the Civil Engineering Laboratory of the University of Minho. Then, all specimens were kept in a climatic chamber under controlled environmental conditions of $20^{\circ} \mathrm{C}$ and $65 \%$ relative humidity $(\mathrm{RH})$ during approximately 2 weeks until they reach a constant weight, (ISO 3131:1975). Only after this stabilization process, the test pieces were submitted to thermal treatments. The selected wood species for this 
study were: Maritime pine (Pinus pinaster), Eucalyptus (Eucalyptus globulus), Beech (Fagus sylvatica), Acacia (Acacia melanoxylon) and Oak (Quercus faginea).

A summary of the full experimental campaign is presented in Table 1.

Table 1. Experimental campaign developed, describing the tests performed and the wood species evaluated.

\begin{tabular}{|c|c|c|c|c|c|c|c|c|c|c|}
\hline \multirow[b]{2}{*}{ Property } & \multicolumn{2}{|c|}{ Maritime pine $(P)$} & \multicolumn{2}{|c|}{ Eucalyptus (E) } & \multicolumn{2}{|c|}{ Beech (B) } & \multicolumn{2}{|c|}{ Acacia (A) } & \multicolumn{2}{|c|}{ Oak (O) } \\
\hline & IT & $T_{0}$ & IT & $T_{0}$ & IT & $T_{0}$ & IT & $T_{0}$ & IT & $T_{0}$ \\
\hline Mass loss & $x$ & $\mathrm{x}$ & $\mathrm{x}$ & $x$ & $x$ & $x$ & $x$ & $x$ & $x$ & $x$ \\
\hline EMC & $x$ & $x$ & $x$ & $x$ & $x$ & $x$ & $x$ & $x$ & $x$ & $x$ \\
\hline $\begin{array}{l}\text { Dimensional } \\
\text { stability }\end{array}$ & $x$ & $x$ & $x$ & $x$ & $x$ & $x$ & $x$ & $x$ & $x$ & $x$ \\
\hline MoE & $x$ & $x$ & $x$ & $x$ & $x$ & $x$ & $x$ & $x$ & $x$ & $x$ \\
\hline MoR & $x$ & $x$ & $x$ & $x$ & $x$ & $x$ & $x$ & $x$ & $x$ & $x$ \\
\hline
\end{tabular}

IT: laboratory Treated; $T_{0}$ : without treatment; EMC: Equilibrium Moisture Content; MoE: Modulus of Elasticity in bending; MoR: Modulus of Rupture in bending.

\section{Thermal treatments}

The thermal treatments applied in this experimental campaign consisted of submitting wood specimens to a certain temperature for a defined period of time, in an oven without induced pressure or control of its oxygen level. Several thermal treatments were applied at constant heating and cooling rates (approximately $3^{\circ} \mathrm{C} / \mathrm{min}$ ). Figure 1 shows a scheme of the thermal treatments applied, being $t_{\mathrm{e}}$ the effective treatment time, in hours, at the maximum temperature, $T_{\max }$.

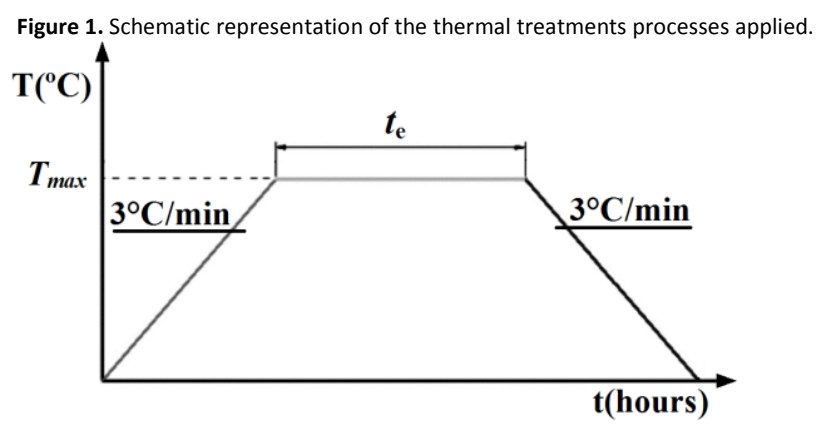

a)

In order to assess the effect of thermal treatments in the selected wood species, specimens treated at different maximum temperatures $\left(T_{\max }\right)$ and under distinct exposure times $\left(t_{\mathrm{e}}\right)$ were compared with untreated ones. Table 2 summarizes the thermal treatments evaluated through the different tested series, pointing out the number of specimens evaluated for each physical (mass loss, EMC and dimensional stability) and mechanical property (MoE and MoR) considered.

Six specimens were selected for each treatment in order to study the physical properties and five for the assessment of the mechanical properties, attempting to cover different temperatures and durations for all species, so as to study the influence of temperature and the increase of its duration in wood properties.

For the study of the mechanical properties, only five specimens were used due to the strict selection without imperfections, before and after the treatments. Severe thermal treatments have influenced the test pieces' shape, not allowing them to be used in the experimental campaign. In addition to this, it was not possible to compare the physical properties of specimens submitted to thermal treatments of $300^{\circ} \mathrm{C}$ during 2 hours because their shape was compromised afterwards and did not have the geometrical characteristics that would allow to obtain measurements 
with the necessary accuracy. This severe temperature was selected as a maximum limited of a possible temperature to be used in the heat treatment.

Table 2. Number of specimens used on the evaluation of physical $(\mathrm{P})$ and mechanical $(\mathrm{M})$ properties by treatment and species.

\begin{tabular}{|c|c|c|c|c|c|c|c|c|c|c|c|c|}
\hline \multirow{2}{*}{ Series } & \multirow{2}{*}{$\begin{array}{l}T_{\max } \\
(\stackrel{o}{ } \mathrm{C})\end{array}$} & \multirow{2}{*}{$\begin{array}{c}t_{e} \\
\text { (hours) }\end{array}$} & \multicolumn{2}{|c|}{ Maritime Pine } & \multicolumn{2}{|c|}{ Eucalyptus } & \multicolumn{2}{|c|}{ Beech } & \multicolumn{2}{|c|}{ Acacia } & \multicolumn{2}{|c|}{ Oak } \\
\hline & & & $P$ & M & $P$ & M & $P$ & $M$ & $P$ & $M$ & $P$ & $M$ \\
\hline$T_{200-2}$ & 200 & 2 & 6 & 5 & 6 & 5 & 6 & 5 & 6 & 5 & 6 & 5 \\
\hline$T_{200-4}$ & 200 & 4 & 6 & 5 & 6 & 5 & - & - & - & - & - & - \\
\hline$T_{200-8}$ & 200 & 8 & 6 & 5 & 6 & 5 & - & - & - & - & - & - \\
\hline$T_{240-2}$ & 240 & 2 & 6 & 5 & 6 & 5 & 6 & 5 & 6 & 5 & 6 & 5 \\
\hline$T_{240-4}$ & 240 & 4 & 6 & 5 & 6 & 5 & - & - & - & - & - & - \\
\hline$T_{240-8}$ & 240 & 8 & 6 & 5 & 6 & 5 & - & - & - & - & - & - \\
\hline$T_{260-2}$ & 260 & 2 & 6 & 5 & 6 & 5 & 6 & 5 & 6 & 5 & 6 & 5 \\
\hline$T_{300-2}$ & 300 & 2 & - & 5 & - & 5 & - & 5 & - & 5 & - & 5 \\
\hline$T_{0}$ & \multicolumn{2}{|c|}{ Untreated } & 6 & 5 & 6 & 5 & 6 & 5 & 6 & 5 & 6 & 6 \\
\hline
\end{tabular}

\section{Mass loss}

In order to evaluate the mass loss caused by the thermal treatments, test specimens with $10 \times 40 \times 40 \mathrm{~mm}^{3}$ (axial $\mathrm{x}$ radial $x$ tangential) were selected from trees of the wood species under study and weighed following four critical stages: i) before thermal treatment when EMC was reached; ii) in anhydrous state before the thermal treatment; iii) when EMC is reached after the thermal treatment; and iv) when dried, in climatic chamber under $20^{\circ} \mathrm{C}$ and $65 \% \mathrm{RH}$, after the thermal treatment.

The procedure used to determine the mass loss evidenced by each wood specimen tested was based on expression (1) suggested by ISO 3130:1975.

$$
\operatorname{mass} \operatorname{loss}(\%)=\frac{M i-M f}{M i} \times 100
$$

Where $M_{\mathrm{f}}$ is the specimen mass after the thermal treatment and $M_{\mathrm{i}}$ is the specimen mass value before the thermal treatment, corresponding to EMC.

\section{Equilibrium moisture content}

The procedure used for determining the specimens' moisture content was based on ISO 3130:1975. All test specimens were immersed in water for 72 hours and then kept in a climatic chamber at $20 \pm 2^{\circ} \mathrm{C}$ and at a relative humidity of $65 \pm 5 \%$. Weightings were carried out with an initial spacing of 3 hours. This spacing was extended when the variation did not justify this need, without influencing the accuracy of the results. Measurements ceased, assuming that the specimens had reached its EMC when the variation in mass was less than $0.1 \%$ at spaced intervals within 24 hours.

\section{Dimensional stability}

Dimensional variation followed the procedure described by ISO 4469:1981, through Equation (2) was determined shrinkage $(\varepsilon)$.

$$
\varepsilon=\frac{l_{1}-l_{2}}{l_{2}} \times 100
$$

Where $I_{1}$ is the size of a given direction of saturated specimen and $I_{2}$ is the size in the same direction for the specimen in anhydrous state.

This experimental procedure has been developed simultaneously with the determination of the equilibrium moisture content, as described in previous section, were made in radial and tangential directions, for all specimens, initially for 
periods of 3 hours, which have been increased to ensure readings when the mass gradient decreased. These measurements were performed until specimens stabilized (ISO 3130:1975).

\section{Modulus of Elasticity (MoE) and Modulus of Rupture (MoR) in bending}

To determine the bending properties of both treated and untreated samples, an experimental campaign was performed following the procedures described by ISO 3133:1975. According to this standard, treated and untreated specimens, with $340 \times 20 \times 20 \mathrm{~mm}^{3}$ (axial $\times$ radial $\times$ tangential), made of the wood species under study, were used to determine the modulus of elasticity (MoE) and the modulus of rupture (MoR) based on a 3-point bending test configuration, as depicted in Figure 2.

Figure 2. Schematic representation of the test setup (a) and specimen (b) used to perform the 3-point bending tests in accordance to ISO 3133:1975. (Dimensions in centimetres).

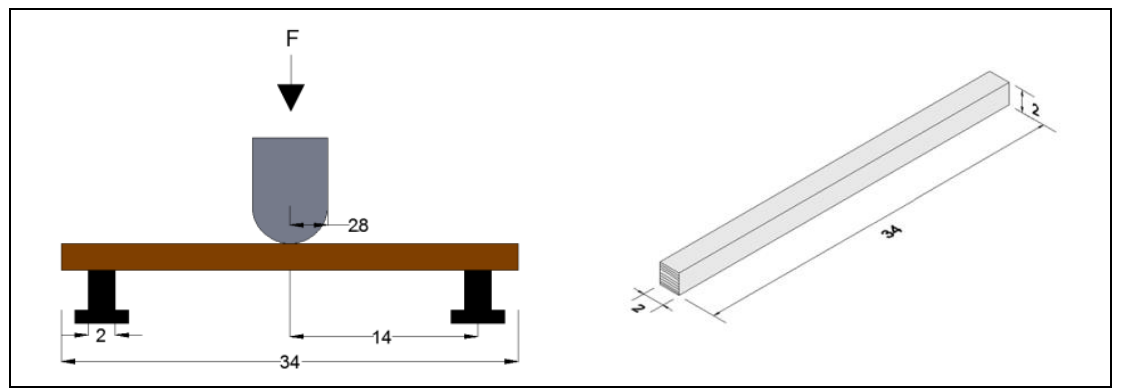

a)

b)

The specimens were selected with these dimensions not only to ensure that an efficient treatment could be applied (higher the volume higher the difficulty to treat with heat) but also to compare with the existing literature. With the same purpose and based on preliminary tests, a constant loading-head movement of $60 \mu \mathrm{m} / \mathrm{s}$ has been adjusted ensuring that maximum load is reached within $300 \pm 120 \mathrm{~s}$. Each test supplied the measurements necessary to quantify the following mechanical properties:

$$
\begin{gathered}
M o E(G P a)=\frac{\Delta \mathrm{F} \times l^{3}}{\Delta x \times 4 \times b \times h^{3}} \\
M o R(M P a)=\frac{3 F \times l}{2 b \times h^{3}}
\end{gathered}
$$

Where $F$ is the maximum load in $\mathrm{N}, \Delta F / \Delta x$ is the slope of the elastic zone in $\mathrm{N} / \mathrm{mm}, l$ is the length of the span between supports, $b$ and $h$ are the section dimensions in $\mathrm{mm}$.

Results and discussion

Tests performed are summarized in table and graphical formats. In the tables are listed the average value and the respective coefficient of variation (CoV) of EMC, the dimensional variation, MoE and MoR. The influence of the treatment temperature $\left(T_{\max }\right)$ and duration $\left(t_{e}\right)$ on the mass loss, EMC, dimensional variation, MoE and MoR is plotted by graphs. Untreated specimens are identified by the acronym $T_{0}$. In some analysis, the focus was kept on the Maritime pine and the Eucalyptus because they are the most representative species in the Portuguese construction.

\section{Mass loss}

It was possible to determine and compare the mass loss achieved in each series of the evaluated specimens. Figure 3 compares the results obtained for the mass loss considering the temperature of the treatment, $T_{\max }$, of $200^{\circ} \mathrm{C}, 240^{\circ} \mathrm{C}$ and $260^{\circ} \mathrm{C}$, during 2 hours $\left(t_{e}\right)$.

As expected, mass loss increases with the severity of the treatment. Higher $T_{\max }$ leads to more expressive mass losses. This behaviour is noticeable in all the studied species and in some cases (Beech and Eucalyptus) it exceeds $10 \%$. Despite Beech presenting a better behaviour until $240^{\circ} \mathrm{C}$, after that point the mass loss increases exponentially, it could be explained by the higher mass loss of lignin when temperatures are near $280^{\circ} \mathrm{C}$ (Figueroa \& Moraes, 2009). The higher degradation of Eucalyptus wood can be explained by the difference in its chemical composition when compared to 
Maritime pine. According to Zaman et al. (2000), Eucalyptus has a bigger hemi-cellulosic fraction, less resistant to thermal degradation than lignin. In the analysis performed by Rodrigues et al. (2001) on the samples of Eucalyptus using FTIR techniques, it was determined that in the case of this wood species, cellulose varied from $43 \%$ to $59.5 \%$ while lignin varied from $23 \%$ to $34 \%$.

Figure 3. Mass loss of the evaluated wood species subjected to different treatment temperatures for a period of exposure of 2 hours $\left(t_{\mathrm{e}}=2\right)$.
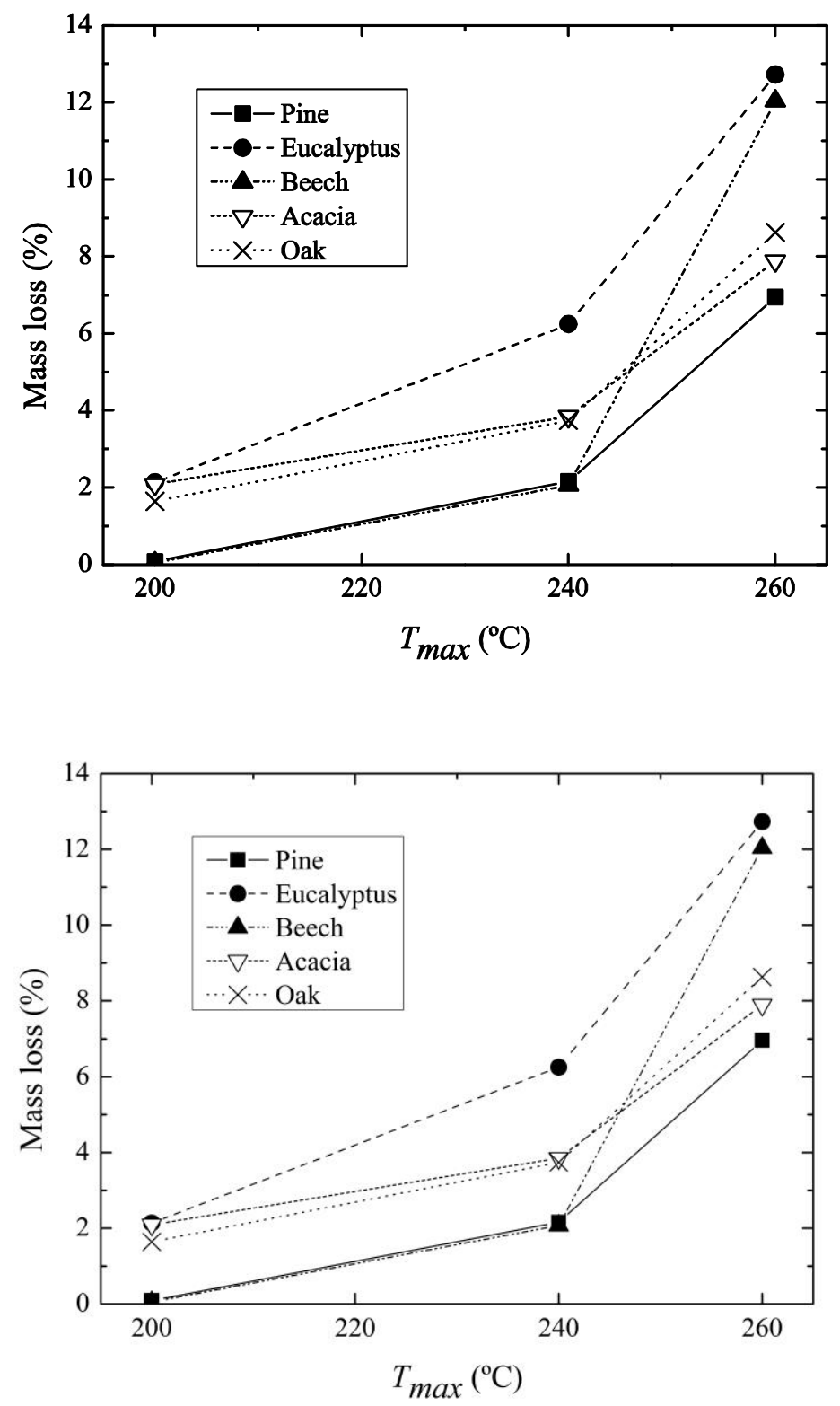

From all the groups, Pine and Acacia revealed average values of approximately $7 \%$ and $8 \%$ for $T_{\max }$ of $260{ }^{\circ} \mathrm{C}$, respectively. These determined mass losses are not much different from those observed by Zaman et al. (2000) for Scots Pine (Pinus sylvestris), a species also existent in Portugal, with approximately $5.7 \%$ to $7.0 \%$ of mass losses by thermal treatments at $205^{\circ} \mathrm{C}$ during 4 to 8 hours.

\section{Equilibrium moisture content}

Table 3 summarizes the results obtained for EMC reduction caused by the thermal treatments considering the effect of $T_{\max }$ for the same time of exposure, $t_{e}$. The values of coefficient of variation (CoV) were, in general, lower than $2 \%$. 


\begin{tabular}{lcccc} 
Table 3. EMC (\%) of the untreated samples $\left(T_{0}\right)$ and treated ones $\left(T_{\max }\right.$ of $200^{\circ} \mathrm{C}, 240^{\circ} \mathrm{C}$ and $\left.260^{\circ} \mathrm{C}\right)$ for an \\
\hline & $T_{0}$ & $T_{200-2}$ & $T_{240-2}$ & $T_{260-2}$ \\
\hline Maritime Pine & 12.7 & 12.0 & 11.4 & 10.0 \\
Eucalyptus & 12.2 & 11.2 & 10.0 & 8.5 \\
Beech & 12.0 & 11.0 & 10.4 & 9.1 \\
Acacia & 10.8 & 10.0 & 9.3 & 8.3 \\
Oak & 11.6 & 11.2 & 10.2 & 8.9 \\
\hline
\end{tabular}

The EMC of all treated specimens decreased in relation to the initially untreated ones. This analysis confirmed that, like mass loss, the rise of treatment temperature causes a bigger reduction of EMC. The results obtained proved to be in line with the existing literature (Jämsä \& Viitanien, 2001; Tjeerdsma et al., 1998; Esteves, 2006), which indicates that $\mathrm{EMC}$ reduces with the increase of intensity of the treatment.

On the other hand, two species were selected for a different $t_{e}$ analysis to compare the average values of a softwood and hardwood species present in Portugal. The effect of the time of exposure $t_{e}$ can be assessed through the analysis of Figure 4, based on specimens of Maritime pine and Eucalyptus treated with a $t_{e}$ of 4 and 8 hours, and a $T_{\max }$ of $200^{\circ} \mathrm{C}$ and $240 \mathrm{C}$.

The results show that, like $T_{\max }, t_{e}$ also influences EMC. Although the results indicate a significant influence of $t_{e}$, it is reasonable to assume the greater influence of the treatment temperature $T_{\max }$ (Militz \& Tjeerdsma, 2000; Rapp, 2001). Considering the different evaluated species, the results obtained show a consistent behaviour of all species. A progressive EMC reduction has been obtained with the rise of $t_{e}$ in the case of Maritime pine and Eucalyptus, by comparing untreated specimens with the ones treated under $200^{\circ} \mathrm{C}$ and $240^{\circ} \mathrm{C}$ during 2,4 and 8 hours. Considering the same treatment temperature $\left(T_{\max }\right)$ and duration $\left(t_{e}\right)$ the decrease of EMC was higher in the case of Eucalyptus, except for $280-8$ case.

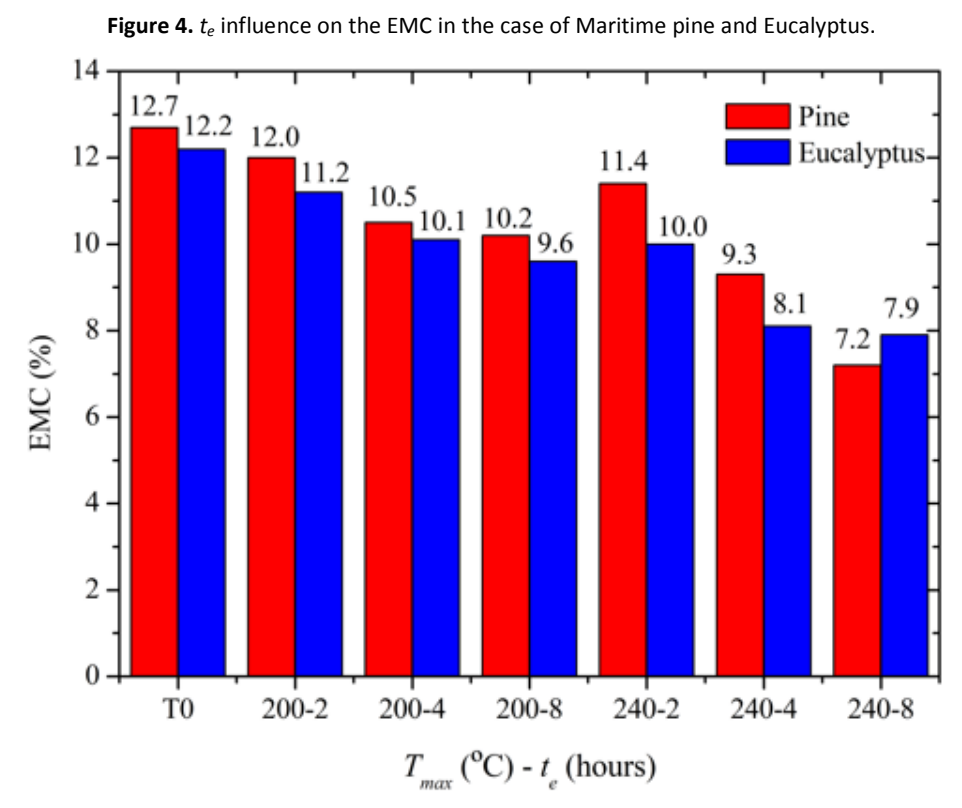

\section{Dimensional stability}

Table 4 summarizes the results obtained for the dimensional variation in the radial direction, for different maximum temperature of treatment $\left(T_{\max }\right)$ and a constant time of exposure $\left(t_{e}\right)$ of 2 hours. By observing these results, it is possible to conclude that the dimensional stability increased with the rise of the intensity of the treatment. Tjeerdsma et al. (1998) obtained a similar behaviour with Beech, Spruce, Scots pine and Monterey pine. As already mentioned in the evaluation of the previous properties, dimensional stability of wood is strongly affected by its hygroscopicity. Reducing the hygroscopicity results in an improvement of the dimensional stability (Militz \& Tjeerdsma, 2000; Hill, 2006). 


\begin{tabular}{lcccc} 
Table 4. Dimensional variation on radial direction (\%) for different $T_{\max }$ and a $t_{e}$ of 2 hours in comparison with untreated specin \\
\cline { 2 - 5 } Species & $T_{0}$ & $T_{200-2}$ & $T_{240-2}$ & $T_{260-2}$ \\
\hline Maritime Pine & $6.5_{(3.4 \%)}$ & $6.4_{(1.6 \%)}$ & $5.3(2.3 \%)$ & $5.1(7.5 \%)$ \\
Eucalyptus & $5.6_{(5.5 \%)}$ & $5.9_{(16.1 \%)}$ & $4.3(4.8 \%)$ & $4.1(7.4 \%)$ \\
Beech & $6.2(4.6 \%)$ & $7.3(6.8 \%)$ & $7.4(7.1 \%)$ & $4.5(5.8 \%)$ \\
Acacia & $5.3(16.8 \%)$ & $4.7(6.5 \%)$ & $4.2(5.3 \%)$ & $3.8(5.9 \%)$ \\
Oak & $4.5(4.9 \%)$ & $5.1(10.7 \%)$ & $4.2(4.8 \%)$ & $3.2(8.1 \%)$ \\
\hline
\end{tabular}

CoV: values between brackets.

The improvement of the dimensional stability was higher in the case of Eucalyptus when compared with Maritime pine subjected to the same conditions. Also, Acacia, revealed a value of $3.8 \%$ for the dimensional variation on the radial direction. In opposition, the specimens of Oak were the ones that presented less important enhancement of the dimensional stability after being treated.

The same analysis was made for the tangential direction. Table 5 summarizes the results obtained for the dimensional variation in the tangential direction, for different maximum temperature of treatment $\left(T_{\max }\right)$ and a constant time of exposure $\left(t_{e}\right)$ of 2 hours. As in the case of radial direction, all the evaluated specimens revealed a consistent behaviour on the dimensional variation on the tangential direction. The dimensional stability increased with the intensity of the treatment. The increment of the maximum temperature $T_{\max }$ led to a decrease of the hygroscopic behaviour of the wood species. Eucalyptus is the wood species that showed a better improvement in the dimensional stability. However, all other species revealed an upgrading of above $40 \%$ on the dimensional stability in the tangential direction.

The influence of the treatment in the dimensional stability can also be assessed based on the evolution of the moisture content (MC). Assuming a time of exposure equal to 2 hours, and based on the behaviour of the Maritime pine specimens, it is possible to conclude that the different treatments led to a reduction of the MC which caused different dimensional variations on the tangential direction.

\begin{tabular}{lcccc}
\multicolumn{5}{c}{ Table 5. Dimensional variation on tangential direction (\%) for different $T_{\max }$ and a $t_{e}$ of 2 hours in comparison with untreated specimens. } \\
\hline Species & $T_{0}$ & $T_{200-2}$ & $T_{240-2}$ & $T_{260-2}$ \\
\hline Maritime Pine & $10.1(3.4 \%)$ & $9.9_{(2.1 \%)}$ & $7.8_{(4.2 \%)}$ & $7.2(5.3 \%)$ \\
Eucalyptus & $8.7(4.2 \%)$ & $7.8_{(3.6 \%)}$ & $4.8(2.6 \%)$ & $4.8(10.1 \%)$ \\
Beech & $9.5(3.7 \%)$ & $9.2(5.0 \%)$ & $8.4(1.4 \%)$ & $6.2(9.2 \%)$ \\
Acacia & $7.2(14.4 \%)$ & $6.5_{(7.6 \%)}$ & $5.7(10.9 \%)$ & $4.3(16.0 \%)$ \\
Oak & $9.8(4.2 \%)$ & $9.8_{(5.0 \%)}$ & $8.5(4.3 \%)$ & $7.1(3.7 \%)$ \\
\hline
\end{tabular}

CoV: values between brackets.

Despite the similar behaviour below MC of approximately $20 \%$, it is possible to identify the minor dimensional variation of treated Maritime pine. The curve of Maritime pine thermally treated at $200^{\circ} \mathrm{C}$ during 2 hours (200-2) reveals a bigger dimensional variation when compared with the curve $240-2\left(T_{\max }=240^{\circ} \mathrm{C} ; t_{\mathrm{e}}=2 \mathrm{~h}\right)$, but a low variation when matched with $T_{0}$ (untreated). The same analogy can be done for the other different states, allowing to conclude that all treatments improve the dimensional stability.

Similar to the analysis performed for the maximum treatment temperature $\left(T_{\max }\right)$, an analysis considering the time of exposure $\left(t_{e}\right)$ as a variable on dimensional stability, was conducted. In Table 6 the results obtained for the dimensional stability analysis in radial and tangential directions, considering a $T_{\max }$ of $200^{\circ} \mathrm{C}$ and $240^{\circ} \mathrm{C}$, during a $t_{e}$ of 4 and 8 hours, are presented for the case of the specimens made of Eucalyptus and also for $t_{e}$ equal to 2 hours in the case of Maritime pine. As expected, the dimensional stability increased for both directions, radial and tangential, with the increase of the time of exposure of the thermal treatment $\left(t_{e}\right)$. 
Table 6. Dimensional variation of Maritime pine and Eucalyptus (\%) for radial and tangential directions considering different $T_{\max }$ and $t_{\mathrm{e}}$

\begin{tabular}{|c|c|c|c|c|}
\hline \multirow[b]{2}{*}{$\begin{array}{l}\text { Series } \\
\left(T_{\text {max-te }}\right)\end{array}$} & \multicolumn{2}{|c|}{ Maritime pine } & \multicolumn{2}{|c|}{ Eucalyptus } \\
\hline & Radial direction & Tangential direction & Radial direction & Tangential direction \\
\hline$T_{0}$ & $6.5(3.4 \%)$ & $10.1(3.4 \%)$ & - & - \\
\hline$T_{200-2}$ & $6.4(<2 \%)$ & $9.9(2.07 \%)$ & - & - \\
\hline$T_{200-4}$ & $5.3(4.4 \%)$ & $9.2(<2 \%)$ & $9.7(4.7 \%)$ & $12.1(4.1 \%)$ \\
\hline$T_{200-8}$ & $5.0(4.9 \%)$ & $8.9_{(<2 \%)}$ & $9.4(3.5 \%)$ & $11.6_{(2.3 \%)}$ \\
\hline$T_{240-2}$ & $5.3(2.3 \%)$ & $7.8(4.2 \%)$ & - & - \\
\hline$T_{240-4}$ & $4.5(6.9 \%)$ & $7.6(2.1 \%)$ & $8.2(2.2 \%)$ & $9.3(2.3 \%)$ \\
\hline$T_{240-8}$ & $3.6(4.8 \%)$ & $5.8(<2 \%)$ & $7.8(5.3 \%)$ & $8.8(<2 \%)$ \\
\hline
\end{tabular}

CoV: values between brackets.

Several studies have shown that mass loss obeys first to a kinetic process, although other studies have shown that this depends on the treatment conditions and on the size of the test sample (Hill, 2006). The results obtained from this analysis are consistent with the existing literature (Bekhta \& Niemz, 2005; Esteves et al., 2007) and, as already mentioned for $T_{\max }$ analysis, the dimensional variation decreases with the increase of intensity of the thermal treatment. A general analysis of the present and former studies revealed a strong influence of $T_{\max }$ when compared with $t_{e}$, which depends on the wood species and its treatment conditions.

\section{Bending}

Modulus of elasticity (MoE) and modulus of rupture (MoR) in 3-point bending tests (Figure 5) of all considered specimens are show in Table 7.

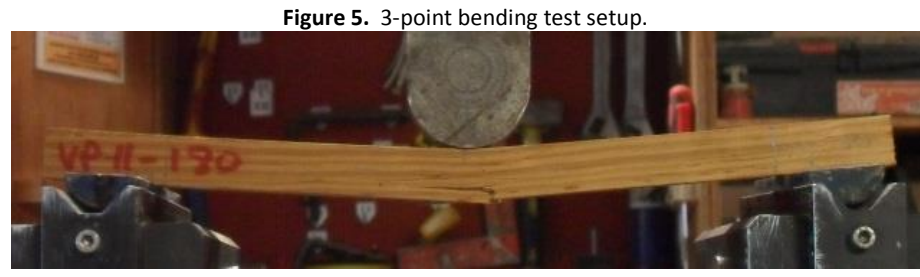

Table 7. MoE values (GPa) obtained in 3-point bending tests for all wood species with a $t_{\mathrm{e}}$ of 2 hours and $T_{\max }$ of $200^{\circ} \mathrm{C}, 240^{\circ} \mathrm{C}, 260^{\circ} \mathrm{C}$ and $300^{\circ} \mathrm{C}$

\begin{tabular}{|c|c|c|c|c|c|c|c|c|c|c|}
\hline Species & $T_{0}$ & $\mathrm{MC}$ & $T_{200-2}$ & $\mathrm{MC}$ & $T_{240-2}$ & $\mathrm{MC}$ & $T_{260-2}$ & $\mathrm{MC}$ & $T_{300-2}$ & $\mathrm{MC}$ \\
\hline \multirow{2}{*}{$\begin{array}{l}\text { Maritime } \\
\text { pine }\end{array}$} & 11.1 & 13.6 & 11.3 & 7.6 (29.9\%) & 10.7 & $6.4(21.8 \%)$ & 11.3 & $5.6(28.1 \%)$ & 7.8 & 4.7 (23.4\%) \\
\hline & $(13.5 \%)$ & $(26.5 \%)$ & $(16.4 \%)$ & & $(17.2 \%)$ & & $(34.9 \%)$ & & $(<2 \%)$ & \\
\hline \multirow[t]{2}{*}{ Eucalyptus } & $14.4_{(5.5 \%)}$ & 19.9 & 15.8 & 4.9 & 12.6 & 3.2 & 14.1 & 2.5 & 4.6 & 3.1 \\
\hline & & $(9.9 \%)$ & (9.1\%) & $(4.9 \%)$ & $(14.9 \%)$ & $(3.2 \%)$ & $(8.6 \%)$ & $(3.5 \%)$ & $(<2 \%)$ & $(3.2 \%)$ \\
\hline \multirow[t]{2}{*}{ Beech } & 11.9 & 13.4 & 12.3 & $6.0(12.4 \%)$ & $9.6(25.8 \%)$ & $5.3(13.4 \%)$ & 10.4 & 3.8 & $8.14_{(<2 \%)}$ & 4.1 (14.5\%) \\
\hline & $(24.0 \%)$ & $(28.9 \%)$ & $(18.5 \%)$ & & & & $(20.2 \%)$ & $(6.1 \%)$ & & \\
\hline \multirow[t]{2}{*}{ Acacia } & $16.1(4.1 \%)$ & 14.2 & 16.4 & $6.6_{(14.5 \%)}$ & 10.9 & $4.6(21.2 \%)$ & 13.0 & 3.9 & $8.4(13.8 \%)$ & 3.8 (18.9\%) \\
\hline & & (18.1\%) & $(7.5 \%)$ & & $(14.9 \%)$ & & $(5.9 \%)$ & $(9.5 \%)$ & & \\
\hline \multirow[t]{2}{*}{ Oak } & 11.3 (9.9\%) & 15.1 & 11.5 & 7.9 (17.8\%) & 10.9 & $4.9(19.1 \%)$ & 11.2 & $4.1(13.2 \%)$ & 10.1 & $3.6(19.4 \%)$ \\
\hline & & $(13.3 \%)$ & $(9.6 \%)$ & & $(16.4 \%)$ & & $(5.2 \%)$ & & $(12.8 \%)$ & \\
\hline
\end{tabular}

MC: Moisture Content; CoV: values between brackets.

The results show a slim increase of MoE in less severe treatments and a decrease with the rise of $T_{\max }$, revealing a behaviour similar to the one observed in the case of other species (Finnish ThermoWood Association, 2003; Jiménez, 2011; Batista, 2012; Santos, 2000). For example, Esteves (2006) obtained an increase of around 7\% of MoE for Maritime pine, for mass losses until $4 \%$ (caused by less severe treatments) and a decrease on more critical treatments.

Based on the results summarized in Table 7, it is possible to conclude that Oak expressed the more stable MoE, while Eucalyptus showed the biggest gradient in this property. However, for treatments of $260^{\circ} \mathrm{C}$ during 2 hours, all species presented an equivalent performance, revealing an increase of $\mathrm{MoE}$, possibly justifiable by its anisotropic characteristic and to a minor variation of the temperature of the treatment. The initial increase of MoE, caused by the treatment of 
$200^{\circ} \mathrm{C}$ during 2 hours, goes from $0.8 \%$ for Maritime pine to $6 \%$ for Eucalyptus. For more severe treatments, of $260^{\circ} \mathrm{C}$ during 2 hours, the decrease observed goes up to $10 \%$ for Oak and up to $25 \%$ for Maritime pine.

In previous studies, the modulus of elasticity was affected up to $5 \%$ for Maritime pine and $15 \%$ for Eucalyptus, but the bending strength was impaired becaue of hemicelulloses and celulloses degradation of up to $40 \%$ for Maritime pine and up to $50 \%$ for Eucalyptus, in the most severe thermal treatments (Esteves, 2006; Rapp, 2001; Bal, 2014).

Table 8 presents the average values obtained for the MoR considering a time of exposure $t_{e}$ equal to 2 hours and a maximum temperature $T_{\max }$ of $200^{\circ} \mathrm{C}, 240^{\circ} \mathrm{C}, 260^{\circ} \mathrm{C}$ and $300^{\circ} \mathrm{C}$. Moreover, the respective gradient in percentage $(\Delta)$ in comparison with the results obtained for untreated specimens, in percentage, is also reported.

Table 8. MoR values (MPa) obtained in the 3-point bending tests for different $T_{\max }$ and a $t_{e}$ of 2 hours in comparison with untreated specimens.

\begin{tabular}{|c|c|c|c|c|c|c|c|c|c|c|c|c|c|c|}
\hline \multirow[b]{2}{*}{ Species } & \multicolumn{2}{|c|}{$T_{0}$} & \multicolumn{3}{|c|}{$T_{200-2}$} & \multicolumn{2}{|c|}{$T_{240-2}$} & \multicolumn{4}{|c|}{$T_{260-2}$} & \multicolumn{3}{|c|}{$T_{300-2}$} \\
\hline & $M_{0} R$ & $\mathrm{MC}$ & $\mathrm{MoR}_{\mathrm{O}}$ & $\Delta$ & $\mathrm{MC}$ & $\mathrm{MoR}_{\mathrm{O}}$ & $\Delta$ & $\mathrm{MC}$ & $\mathrm{MoR}_{\mathrm{O}}$ & $\Delta$ & $\mathrm{MC}$ & $M_{O} R$ & $\Delta$ & $\mathrm{MC}$ \\
\hline \multirow[t]{2}{*}{ Maritime Pine } & 130 & 13.6 & 127 & -2.3 & 7.6 & 104 & -20.0 & 6.4 & 76 & -41.5 & 5.6 & 51 & -60.8 & $4.7_{(23.4 \%)}$ \\
\hline & $(21.5 \%)$ & $(26.5 \%)$ & $(17.4 \%)$ & & (29.9\%) & $(12.2 \%)$ & & (21.8\%) & $(24.2 \%)$ & & (28.1\%) & $(11.0 \%)$ & & \\
\hline \multirow[t]{2}{*}{ Eucalyptus } & 129 & 19.9 & 105 & -18.6 & 4.9 & 86 & -33.3 & 3.2 & 91 & -29.5 & 2.5 & $28(8.2 \%)$ & -78.3 & 3.1 \\
\hline & $(5.9 \%)$ & $(9.9 \%)$ & $(21.7 \%)$ & & $(4.9 \%)$ & $(25.6 \%)$ & & $(3.3 \%)$ & $(13.9 \%)$ & & $(3.5 \%)$ & & & $(3.2 \%)$ \\
\hline \multirow[t]{2}{*}{ Beech } & 146 & 13.4 & 167 & +14.4 & 6.0 & 124 & -7.4 & 5.3 & 105 & -21.6 & 3.8 & 52 & -61.2 & $4.1_{(14.5 \%)}$ \\
\hline & $(26.6 \%)$ & $(28.9 \%)$ & $(6.5 \%)$ & & (12.4\%) & $(11.5 \%)$ & & (13.4\%) & $(21.6 \%)$ & & $(6.1 \%)$ & $(12.0 \%)$ & & \\
\hline \multirow[t]{2}{*}{ Acacia } & 138 & 14.2 & 141 & +2.1 & 6.6 & 83 & -39.9 & 4.6 & 82 & -40.6 & 3.9 & 47 & -65.9 & $3.8_{(18.9 \%)}$ \\
\hline & $(6.7 \%)$ & (18.1\%) & $(2.8 \%)$ & & $(14.5 \%)$ & $(9.7 \%)$ & & $(21.2 \%)$ & $(2.8 \%)$ & & $(9.5 \%)$ & $(28.9 \%)$ & & \\
\hline \multirow[t]{2}{*}{ Oak } & 102 & 15.1 & 91 & -10.8 & 7.9 & 83 & -18.6 & 4.9 & 74 & -27.5 & 4.1 & 68 & -33.3 & $3.6_{(19.4 \%)}$ \\
\hline & $(9.2 \%)$ & $(13.3 \%)$ & $(12.6 \%)$ & & $(17.8 \%)$ & $(20.2 \%)$ & & (19.1\%) & $(3.0 \%)$ & & $(13.2 \%)$ & $(12.8 \%)$ & & \\
\hline
\end{tabular}

$\Delta=\left(\mathrm{T}_{T \max -\mathrm{te}}-T_{0}\right) / T_{0} ;$ CoV: values between brackets; MC: Moisture content.

An average decrease of the bending strength can be observed following the rise of the severity of the treatment, with a reasonable variability coefficient (around 20\%). Particularly, Oak presented a small reduction of bending strength when compared with the untreated specimens of the same species. In an other hand, treated Maritime pine has presented a decrease on the bending strength of $3 \%$ up to $60 \%$, with lower average values when compared with other species presented in the existing literature. For example, Bengtsson et al. (2002) obtained a reduction in bending strength of $50 \%$ for Spruce and $47 \%$ for Scots pine treated at $220^{\circ} \mathrm{C}$, while the obtained values for Maritime pine are a reduction of $20 \%$ for a temperature of $240^{\circ} \mathrm{C}$ for 2 hours of exposition.

In the graphical form, by analysing Figure 6, it is possible to note that the decrease of MoR is quite similar for all species with a slight reduction in the case of the Maritime pine and much less expressive for Oak. In conclusion, it is possible to point out that the bending strength is influenced by thermal treatment conditions (maximum temperature and time of exposure).

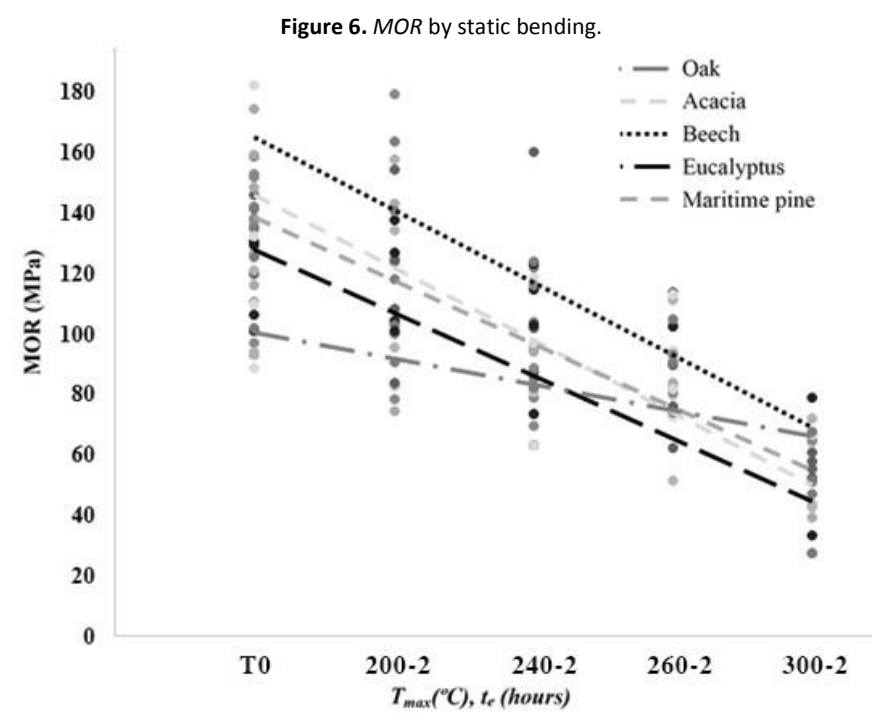

The influence in the mechanical properties, with their reduction, increases with the severity of the thermal treatment. Although the decrease of MoR occurs, this varies according to the applied thermal treatment. With a decrease of approximately $2.3 \%$, Maritime pine revealed the best performance in the less severe treatment (200-2). However, Oak 
showed a more consistent behaviour and a lesser decrease with the rise of temperature treatments. Eucalyptus exhibited the higher decrease of mechanical properties, intensified by the severity of the applied thermal treatments. Unexpectedly, Beech manifested an increase of MoR (15\%), event not supported by the existing literature, it is possible explainable through the reduction of the moisture content (from $13.4 \%$ to $6.0 \%$ ). This increase occurred just for the thermal treatment at $200^{\circ} \mathrm{C}$ ( 2 hours) and was completely reverted with the rise of the severity of the treatments, just like in the case of the other species studied.

Moreover, bending tests were performed with the additional objective of evaluating the influence of the time of exposure $\left(t_{e}\right)$ considering the maximum temperatures of $200^{\circ} \mathrm{C}$ and $240^{\circ} \mathrm{C}$ for the treatment on Maritime pine and Eucalyptus. Table 9 presents the results obtained for the MoR of untreated and thermally treated Maritime pine and Eucalyptus specimens $\left(T_{0}\right)$ during 2,4 and 8 hours, under $200^{\circ} \mathrm{C}$ and $240^{\circ} \mathrm{C}$ and the respective gradient in percentage $(\Delta)$ in comparison with the results obtained for untreated test pieces, in percentage.

A decrease in the MoR can be observed due to the prolonged duration of the treatment. Despite the steeper decline of both species subjected to more severe treatments, a reduction of bending strength is revealed in function of the prolonged treatment duration of 2 to 4 hours. Although results do not clearly reveal an exact reduction in the period of 4 to 8 hours, it is possible to observe a consistent and pronounced reduction when compared with the untreated state. The decrease of MoR proved to be consistent for both temperatures $\left(200^{\circ} \mathrm{C}\right.$ and $\left.240^{\circ} \mathrm{C}\right)$, intensified by the increase of the duration of the treatment.

Table 9. MoR values (MPa) obtained in the 3-point bending tests considering different $T_{\max }$ and $t_{e}$ on Maritime pine and Eucalyptus specimens.

\begin{tabular}{|c|c|c|c|c|c|c|}
\hline \multirow[b]{2}{*}{ Series } & \multicolumn{3}{|c|}{ Maritime pine } & \multicolumn{3}{|c|}{ Eucalyptus } \\
\hline & MoR & $\Delta$ & $\mathrm{MC}$ & MoR & $\Delta$ & $\mathrm{MC}$ \\
\hline$T_{0}$ & $130.0_{(21.5 \%)}$ & - & $13.6(26.5 \%)$ & $129.0_{(5.9 \%)}$ & - & $19.9(9.9 \%)$ \\
\hline$T_{200-2}$ & 127 (17.4\%) & -2.3 & $7.6(29.9 \%)$ & $105.0_{(21.7 \%)}$ & -18.6 & $4.9(4.9 \%)$ \\
\hline$T_{200-4}$ & $91.6(17.1 \%)$ & -29.5 & 7.9 (25.1\%) & $119.0_{(15.4 \%)}$ & -7.8 & $4.1(6.4 \%)$ \\
\hline$T_{200-8}$ & 92.4 (14.9\%) & -28.9 & $7.0(15.4 \%)$ & 74.0 (36.3\%) & -42.6 & $6.9(1.0 \%)$ \\
\hline$T_{240-2}$ & $104.0(12.2 \%)$ & -20 & $6.4(21.8 \%)$ & $86.0(25.6 \%)$ & -33.3 & $3.2(3.3 \%)$ \\
\hline$T_{240-4}$ & $49.3(32.4 \%)$ & -62.1 & $6.8(17.0 \%)$ & $73.8(45.4 \%)$ & -42.8 & $3.5(4.9 \%)$ \\
\hline$T_{240-8}$ & $58.4(18.1 \%)$ & -43.8 & $5.9(21.2 \%)$ & $78.6(32.1 \%)$ & -39.1 & 3.1 (9.3\%) \\
\hline
\end{tabular}

$\Delta=\left(T_{\text {Tmax-te }}-T_{0}\right) / T_{0} ;$ CoV: values between brackets; MC: Moisture content.

Bengtsson et al. (2002) reached to the same conclusion and observed similar results for Spruce and Scots pine, where a decrease of bending strength capacity was notably obtained due to a comparative inferior hemicellulose. These results are in line with other tests performed with the same species, where the reduction of MoR is the result of the chemical changes induced by the thermal treatment that reveals to be more expressive for Eucalyptus than Maritime pine.

The mechanical properties were affected due to the selective chemical changes occurring in wood structural components (Rodrigues, 1998; Esteves et al., 2013; Allegretti et al., 2012).

Conclusions

The main goal of the present work was to study the influence of thermal treatment on the properties of wood from most important species available in Portugal. Thermal modification affects the physical and mechanical properties of wood. This kind of treatment causes the degradation of some important wood elements, like hemicelluloses, that leads to mass losses. The more intense the treatment, the higher it is the loss of those wood constituents (Esteves, 2006; Militz \& Tjeerdsma, 2000; Boonstra, 2008).

Thermal treatments simulated in this study led to a reduction of hygroscopicity, and consequently, to a reduction of EMC improving the dimensional stability. The gains observed on these properties increase with the severity of the applied thermal treatment.

Like physical properties, mechanical properties were also affected by thermal treatments. Despite a short rise of MoE in less severe treatments, this property was reduced by the increase of thermal treatments severity. MoR also shows a decrease due to the severity of the thermal treatment applied. These properties decline, in correlation with the 
temperature treatment $\left(T_{\max }\right)$, and the treatment duration $\left(t_{e}\right)$. On both cases the mechanical performance is reduced by the increase of the severity of the treatment.

In a more detailed analysis, in the case of the thermal treated Maritime pine at $200^{\circ} \mathrm{C}$, capacity loss was less than $3 \%$, then for any strength class in question, non-change would occur. However, for treatments at $240^{\circ} \mathrm{C}$, the decrease was approximately of $20 \%$. In this case, the strength class would be one classification down (after treatment), but still viable for structural applications.

In summary, the results obtained in this study are aligned with the existing literature for the different species studied until this moment (Esteves, 2006; Esteves et al., 2007; Santos, 2000; Rodrigues et al., 1998), confirming the efficiency of the applied simulated thermal treatment. This preliminary study aimed to promote the development of TMW using Portuguese species. A first approach on the consequences of the thermal treatment on the dimensional stability and bending properties was assessed. The results here presented will constitute an important background on the development of further studies and, more important, in the development of thermal modified wood species.

\section{Acknowledgements}

The support given by Portuguese industry Santos \& Santos through the supply of the wood specimens used in the experimental campaign is acknowledged.

References

Allegretti O., Brunetti M., Cuccui I., Ferrari S., Nocetti M., \& Terziev N. (2012). Thermo-vacuum modification of spruce (Picea abies Karst.) and fir (Abies alba Mill.) wood. BioResources, 7(3), 3659-3669. DOI: 10.15376/biores.7.3.3659-3669.

Bal B.C. (2014). Some physical and mechanical properties of thermally modified black Pine wood. European Journal of Wood and Wood Products, 72(1), 61-66.

Batista D.C. (2012). Modificação Térmica da Madeira de Eucaliptus grandis em escala industrial pelo processo Brasileiro Vap HolzSysteme ${ }^{\circledR}$. Doctoral Thesis. Universidade Federal do Paraná. Setor de Ciencias Agrárias. (In Portuguese).

Bekhta P., \& Niemz P. (2005). Effect of high temperature on the change in color, dimensional stability and mechanical properties of spruce wood. Holzforschung, 57(5), 539-546.

Bengtsson C., Jermer J., \& Brem F. (2002). Bending strength of heat-treated spruce and pine timber. In International Research Group Wood Pre, Section 4-Processes, No. IRG/WP 02-40242.

Burmester A. (1975). Dimensional stabilization of wood. Holz Roh-Werkst, 33(9),333-335.

Boonstra, M. (2008). A two-stage thermal modification of wood. Doctoral thesis in applied biological sciences: soil and forest management. Henry Poincare' University-Nancy, France.

Boonstra M., Tjeerdsma B., \& Groeneveld H. (1998). Thermal modification of non-durable wood species 1 . The Plato technology: thermal modification of wood, International Research Group Wood Pro, section 4: processes. 29 Annual meeting, Maastricht, June 14-19, p 13.

Chaouch M., Dumarcay S., Pétrissans A., Pétrissans M., \&

Gérardin, P. (2012). Effect of heat treatment intensity on some conferred properties of different European softwood and hardwood species. Wood Science Technology, 47,663-673. DOI 10.1007/s00226-013-0533-z.

Esteves B. (2006). Technological Improvement of Portuguese Woods by Heat Modification. Doctoral Thesis in Environmental Engineering. School of Agronomy. Technical University of Lisbon.

Esteves B., \& Pereira H. (2009). Wood modification by heat treatment: a review, BioRes., 4(1), 370-404.

Esteves B., Domingos I., \& Pereira H. (2007). Improvement of technological quality of eucalyptus wood by heat treatment in air at $170-260$ 드, Forest Products Journal, 57(1/2), 47-52.

Esteves B., Domingos I., \& Pereira H. (2013). Comparison between heat treated sapwood and heartwood from Pinus pinaster. Eur. J. Wood Prod., $72(1), 53-60$.

Esteves B., Domingos I., Velez Marques A., Nunes L., \& Pereira H. (2006). Variation of Dimensional Stability and Durability of Eucalyptus Wood by Heat Treatment. ECOWOOD 2006 - 2nd International Conference on Environmentally compatible Forest Products. Fernando Pessoa University, Porto, Portugal.

Figueroa M.J.M., \& Moraes P.D. (2009). Comportamento da madeira a temperaturas elevadas. Ambiente Construído, Porto Alegre, v. 9, n. 4:157-174. (In Portuguese).

Finnish ThermoWood Association. (2003). ThermoWood ${ }^{\circledR}$ Handbook. Helsinki, Finland. 
Hakkou M., Pétrissans M., Géardin P., \& Zoulalian A. (2006). Investigations of the reasons for fungal durability of heat-treated Beech wood. Polymer Degradation and Stability, 91(2), 393-397.

Hill C.A. (2006). Wood Modification: Chemical, Thermal and Other Processes. John Wiley \& Sons, Ltd.

ISO 3130 (1975). Wood - Determination of moisture content for physical and mechanical tests. International Organization for Standardization.

ISO 3131 (1975). Wood - Determination of density for physical and mechanical tests. International Organization for Standardization.

ISO 3133 (1975). Wood - Determination of ultimate strength in static bending. International Organization for Standardization.

ISO 4469 (1981). Wood - Determination of radial and tangential shrinkage. International Organization for Standardization.

Jämsä S., \& Viitaniemi P. (2001). Heat treatment of wood - Better durability without chemicals, Proceedings of special seminar held in Antibes, France.

Jimenez J.M. (2011). Physico-Mechanical Properties and Durability of Thermally Modified Malapapaya [Polyscias nodosa (Blume) Seem.] Wood. Philippine Journal of Science, 140(1), 13-23.

Johansson D. (2008). Heat treatment of solid wood: Effects on absorption, strength and colour. Doctoral Thesis. Luleå University of Technology, Sweden. 142p.

Militz H., \& Tjeerdsma B. (2000). Heat treatment of wood by the Plato-process: Proceedings of Seminar "Production and development of heat treated wood in Europe", Nov. 2000, Helsinki, Stockholm, Oslo.

Pentti E., Jämsä S., Viitanen H., \& Viitaniemi P. (1993). Method for improving biodegradation resistance and dimensional stability of cellulosic products.

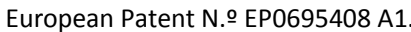

Rapp A.O. (2001). Review on heat treatments of wood. COST ACTION E22 Environmental optimisation of wood protection. Proceedings of Special Seminar held in Antibes, France on 9 February 2001.

Rodrigues J., Faix O., \& Pereira H. (1998). Determination of lignin content of Eucalyptus globulus wood using FTIR spectroscopy. Holzforschung, 52,4650 .

Rodrigues J., Puls J., Faix O., \& Pereira H. (2001). Determination of monosaccharide composition of Eucalyptus globulus wood by FTIR spectroscopy. Holzforschung, 55,265-269.

Santos J.A. (2000). Mechanical behaviour Eucalyptus wood modified by heat. Wood Science and Technology, 34(2000),39-43.

Tjeerdsma B., Boonstra M., \& Militz H. (1998). Thermal modification of nondurable wood species: improved properties of thermally treated wood, International Research Group on Wood Preservation, document № IRG/WP 98-40124.

Verbist M., Nunes L., Jones D., \& Branco J.M. (2018). Chapter 11: Service life design of timber structures. Long-term Performance and Durability of Masonry Structures - Degradation Mechanisms, Health Monitoring and Service Life Design - Part III: Long-term performance and service life design. 1st Edition. Ghiassi, B., \& Lourenço P.B. (Eds.). November 1, 2018. ISBN 9780081021101

Vukas N., Horman I., \& Hajdarević S. (2010). Heat Treated Wood. 14th International Research/Expert Conference "Trends in the Development of Machinery and Associated Technology" TMT 2010, Mediterranean Cruise.

Zaman A., Alen R., \& Kotilainen R. (2000). Thermal behavior of Pinus sylvestris and Betula pendula at 200-230 ${ }^{\circ} \mathrm{C}$. Wood Fiber Science, 32(2),138-143. 